\title{
1. Contributions on entrepreneurial behaviour research
}

\author{
Susana C. Santos, Craig Mitchell, Hans \\ Landström, Alain Fayolle and António Caetano
}

\subsection{AIMS AND SCOPE OF THE BOOK}

This is the seventh book in the book series 'European Research in Entrepreneurship', which continues to contribute to advance entrepreneurship research in Europe. In the book series a rich variety of European research in the field of entrepreneurship is presented, and in this volume of the book series we focus in particular on our knowledge of entrepreneurial behaviour. The aim of the book is to provide new insights on entrepreneurial behaviour from young European scholars in entrepreneurship, and the book will provide university teachers, researchers but also policy-makers with a lot of novel insights within the field of entrepreneurial behaviour.

The content of the book is based on the contribution from scholars and doctoral students involved in the European University Network on Entrepreneurship (ESU - http://www.esu-network.eu/). The ESU Network is a common space for those who are interested in sharing knowledge and experience about entrepreneurship research and education within the European culture. In existence for fifteen years, ESU is a relevant constructive and collaborative platform that has been making a difference in entrepreneurship research and doctoral education in Europe. This book series is an output of this joint research community that has been established in Europe.

The chapters in the book are divided into three parts. In the first part of the book we pay particular attention to the entrepreneur as an individual, and present three chapters (Chapters 2 to 4 ) on entrepreneurial intentions. The focus on the individual will continue in the second part of the book, but we centre our interest on how entrepreneurship behaviour could be trained and learnt. In these four chapters (Chapters 5 to 8) the authors discuss different aspects of entrepreneurship education. Finally, in the third section of the book, we change the level of analysis from the 
individual to the organization, and in three chapters (Chapters 9 to 11) the authors elaborate on different aspects of 'entrepreneurial orientation'.

\subsection{THE EMERGENCE OF OUR KNOWLEDGE ON ENTREPRENEURIAL BEHAVIOUR}

Over the last 40 years, entrepreneurship has become one of the most popular fields of research in management studies. Initially, the research was heavily dominated by an interest in searching for the personality and traits of the entrepreneur as an individual. For example, it was shown that entrepreneurs were assumed to be characterized by a high need for achievement, internal locus of control, risk-taking, tolerance of ambiguity, and values which differentiated entrepreneurs from non-entrepreneurs.

However, this strand of research was strongly criticized and more or less regarded as a 'dead-end' in entrepreneurship research, and in the late 1980s and early 1990s there was a systematic shift in research - from a focus on the entrepreneur as an individual towards the entrepreneurial process and behaviour. One influential contribution in the shift towards a behavioural focus of entrepreneurship research was William Gartner's seminal work "Who is an entrepreneur?" Is the wrong question', published in 1988. Gartner was one of the first to claim that entrepreneurship research ought to pay more attention to behavioural aspects of entrepreneurship, that is, focus on what the entrepreneur does, and less on who he/she is. In Gartner's view entrepreneurship is seen as a set of activities involved in the creation of organizations (Landström and Åström, 2011).

Gartner's 1988 article can be considered as a starting point for the shift in entrepreneurship from a focus on entrepreneurial traits and characteristics to an increased interest in behavioural aspects of entrepreneurship. Since the early work by William Gartner, a great number of scholars have paid attention to the behavioural aspects of entrepreneurship, and since the early 1990s entrepreneurial behaviour has become an important part of entrepreneurship research. At the same time the concept of 'entrepreneurship' has been broadened - to include not only the creation of organizations, but activities and practices in order to identify and pursue different kinds of opportunities. Over the years, several streams of interest with a focus on entrepreneurial behaviour have emerged. In this book we will elaborate on three strands of entrepreneurial behaviour research: entrepreneurial intentions, entrepreneurial learning and entrepreneurial orientation. 


\subsection{INTENTION RESEARCH IN ENTREPRENEURSHIP}

Intentions, that is, future-oriented conscious thoughts that include both an outcome (or a goal) and an action plan for achieving the outcome (Tubbs and Ekeberg, 1991), could be regarded as a key construct in the behaviour of entrepreneurs and the process of venture creation. Intentions could be seen as a precursor of entrepreneurial action, even though the correlation between intention and action is in most empirical studies rather moderate. Barbara Bird could be seen as one of the pioneers on entrepreneurial intentions. In her seminal article 'Implementing entrepreneurial ideas: the case for intention' in the Academy of Management Review in 1988, based on her dissertation work, she assumed that the entrepreneurial intention process was based on individual differences operated through three intention mechanisms: (1) 'temporal tension', which reflected the discrepancy between what exists and the desire for the future; (2) 'strategic focus', which distinguished between an end-focus and the focus on the means to achieve the goals; and (3) 'intentional posture', positioning the entrepreneur and the venture in relationship to internal cognitions and motivations, but also in relationship to the outer world. Bird's reasoning was rather static, but should be seen in relation to other models developed at that point in time, for example, Shapero and Sokol (1982), who talked about venture creation in terms of an outcome of the individual's displacement, perceived desirability and perceived feasibility - a model that later on was elaborated by Krueger and Carsrud (1993), Krueger and Brazeal (1994), and Krueger et al. (2000), using Ajzen and Fishbein's (1969) 'theory of planned behaviour' (TPB) as the basic theoretical framework. TPB posits intentions as a result of (1) the individual's attitude toward a certain behaviour; (2) subjective norms, that is, the values others have about the behaviour; and (3) the perceived behavioural control.

Since these early contributions, entrepreneurial intention research, often based on TPB as the main theoretical framework, has become one of the most strongly developed areas within entrepreneurship research, and the model has been validated across many domains and contexts. Related to this development, the contributions in this book volume are addressed in three chapters.

Chapter 2 is entitled 'Connecting the literature dots: a literature review on prototypes in entrepreneurship research' and is contributed by Costa, Caetano, Frederiks and Santos. The authors develop a systematic literature review on prototype theory within entrepreneurship research, providing a deeper understanding on how these cognitive structures trigger entrepreneurial activity. Following the well-established procedures for 
systematic literature reviews, the authors identified 11 articles published between 1973 and 2014. Key findings showed that prototypes are knowledge structures which account for an explanation of entrepreneurial specific attributes, and particularly to the opportunity recognition stage of the entrepreneurial process. Prototypes are found to be relevant both for pattern recognition and structural alignment in opportunity recognition. Based on this systematic literature review, the authors draw a theoretical model to inform future research concerned with exploring the development of cognitive structures in entrepreneurial settings.

Moving away from the cognitive foundations of entrepreneurial behaviour, Chapter 3 is entitled 'Entrepreneurial potential among individuals with different entrepreneurial experience' and describes the pattern of key individual entrepreneurial competencies at different stages of the entrepreneurship process. Santos, Caetano, Costa and Neumeyer argue that individuals with different entrepreneurial experience will exhibit distinct patterns on the entrepreneurial potential dimensions. Based on the Global Entrepreneurship Monitor (GEM) model and data collected in Portugal in 2011, the authors compared five groups of individuals with different entrepreneurial experience: nascent entrepreneurs $(\mathrm{N}=90)$, owner-managers of young firms $(\mathrm{N}=41)$, owner-managers of established firms $(\mathrm{N}=105)$, future entrepreneurs $(\mathrm{N}=44)$, and non-entrepreneurs $(\mathrm{N}=87)$. The authors used a reduced version of the Entrepreneurial Potential Assessment Inventory and the main results showed that there are significant differences between non-entrepreneurs and individuals with different levels of entrepreneurial experience. More specifically, nonentrepreneurs showed lower scores in all the dimensions of the entrepreneurial potential except in risk aversion. Future entrepreneurs showed to be significantly different from nascent entrepreneurs and owner-managers of young firms, but nascent entrepreneurs, owner-managers of young firms, and owner-managers of established firms are not so different from each other. These results are discussed in line with the individual perspectives of entrepreneurs.

In trying to understand the entrepreneur as an individual, entrepreneurial intentions is one of the most prominent constructs. Chapter 4 focuses on the 'Individual and cultural values as psychosocial cognitive antecedents and moderators of entrepreneurial intentions' and was developed by Belchior and Liñán. Building on the theory of planned behaviour, the authors develop a conceptual model on the influence of individual and cultural values as social factors that condition the formation of entrepreneurial intentions. Delving into the theory of planned behaviour and integrating the individual and cultural values, the authors put forward a set of seven theoretical propositions that open new avenues for future empirical 
research. Furthermore, this innovative theoretical piece contributes to a more comprehensive perspective on how entrepreneurial intentions are formed, and how they are conditioned by social factors.

To sum up, Part I of this book volume offers three innovative complementary perspectives and approaches on the individual perspective of entrepreneurship. Grounded on cognitive theory and using a systematic literature review, Costa and colleagues uncover how prototype theory has been contributing to understand opportunity recognition and proposes new research paths. This chapter contributes to identify key established principles using the cognitive lens on opportunity recognition and, at the same time, acknowledges that internal and affective variables have also to be taken into consideration when attempting to develop and learn prototypical features of business opportunities. In the next chapter, Santos and colleagues go back to the psychosocial characteristics of entrepreneurs, and compare individuals with different levels of entrepreneurial experiences. This empirical study contributes to strengthen the role of individual characteristics in different stages of the entrepreneurship process, and to capture an 'individual-situation' perspective of entrepreneurship. Finally, Belchior and Liñán contribute to the theory of planned behaviour in entrepreneurship, and present individual and culture values as antecedents of entrepreneurial intentions. This is a framework that contributes to the theoretical development of intentions, and opens new insights for conceptual and empirical advancements in entrepreneurial intentions.

\subsection{ENTREPRENEURSHIP EDUCATION AND LEARNING RESEARCH}

Entrepreneurial behaviour is not always obvious for most individuals it needs to be learnt. For a long time there has been an interest in promoting entrepreneurial behaviour through education efforts. Since the early 1980s, entrepreneurship education has shown significant growth within universities in the US as well as across Europe. However, there is still an intense scholarly debate on the forms for such education (Neck and Greene, 2011; Fayolle, 2008, 2013; Kyrö, 2015).

In Europe seminal work on entrepreneurship education and learning was presented by Alan Gibb (1987) and Bengt Johannisson (1991). The focus of these contributions was to discuss what entrepreneurship means when implemented in educational settings and the kind of learning necessary to become an entrepreneur. For a long period of time, entrepreneurship education research was very descriptive, with a focus on the curriculum and program content in entrepreneurship education, and the 
knowledge skills, values and abilities that are supportive of entrepreneurship. Another feature emphasized at the time was the multiplicity of objectives in entrepreneurship education with respect to the content ('what') students should learn, but also an interest in the use of unconventional experiential programs (Hägg and Gabrielsson, 2017). However, it is not until recently that scholars have started to explicitly address the issue of pedagogy in entrepreneurship (Fayolle and Gailly, 2008; Neck and Greene, 2011; Williams Middleton and Donnellon, 2014).

Thus, the debate on 'what' students should learn has continued, but we have seen an intense discussion about 'how' (methods) to teach aspects of entrepreneurship. However, what is needed is a stronger theoretical anchor of our pedagogical approaches in entrepreneurship. Pittaway and Cope (2007) even argue that the debate on pedagogy in entrepreneurship education has run ahead of the theoretical development, and they call for a stronger theoretical foundation within the area.

The authors of Chapters 5 to 8 address some of the shortcomings raised in this debate. Chapter 5, 'Promoting entrepreneurship in an unfavourable setting: a case study of a university programme in Malaysia', by Rashan Shah Robuan, Jaén and Liñán, describes a case study of a newly implemented entrepreneurship education program at one public university in Malaysia. Grounded on the theory of planned behaviour, this study focuses on the difficulties involved in the implementation of the program across campus (multi-discipline) and on a multi-ethnic setting, especially with regard to the ultimate objective of the entrepreneurship education program to help solve the low participation of Bumiputera ethnic groups in entrepreneurship. This case study describes the entrepreneurship education program and the characteristics of the participating students from the basic $(\mathrm{N}=308)$, intermediate $(\mathrm{N}=17)$ and advanced $(\mathrm{N}=19)$ courses. The results suggest that the initial interest in entrepreneurship is lower for the Bumiputera ethnic group, and participants in the elective courses exhibit higher entrepreneurial intention when compared to those taking the compulsory course. This study shows the particular aspects of entrepreneurship education in unique contexts and provides relevant contributions for the implementation and management of entrepreneurship education.

Chapter 6 targets the 'Formal mentorship in experiential entrepreneurship education: examining conditions for entrepreneurial learning among students' and is developed by Hägg and Politis. This study examines how formal mentorship as a pedagogical method facilitates learning for students engaged in experiential entrepreneurship education. Using a diary-interview methodology, the authors followed the learning experience and outcomes of a group of students who have been assigned mentors to aid them in their personal and professional development as 
entrepreneurs. Main results identified critical conditions for establishing mentorship relations that generate a learning process beneficial for student entrepreneurs. This study provides explanations for why certain mentorship relations are associated with different forms of learning outcomes depending on how the relations mature over time.

Collaborative teaching methods are commonly used in entrepreneurship education, and these methods are explored by Lyons, Lynn and Mac an Bhaird in Chapter 7, entitled 'Social loafing in student entrepreneurship teams'. The authors argue that despite the benefits of improved retention of information, motivation, critical reasoning, communication and social skills often associated with collaborative learning, within a context of entrepreneurship education these outlined benefits are dependent on the efficiency of the team and their teamwork. Despite teamwork being a common element in entrepreneurship education, the authors conclude from their literature review that we actually have a limited knowledge of the mechanism of teamwork within student teams in entrepreneurship education. The authors focus the attention of their study on the problem of social loafing or 'free-riding' within these teams. Beyond their findings that social loafing is a very real problem, which is fairly prevalent in student teams, the authors also advocate the use of the team signatory code as a teaching instrument to improve pedagogical practices within team-based and collaborative learning. According to the authors, the benefits of such an approach are twofold: first, students are allowed to evaluate and recognize their value within the context of a team, and secondly, as a method to predict team performance and social loafing at later stages of the teamwork.

The last chapter of the second part of this book series volume is entitled 'Perceived learning outcomes of experiential entrepreneurship education: the case of Latvian business schools'(Chapter 8), contributed by Kozlinska, Mets and Rõigas. This chapter addresses the lack of empirical evidence that the experiential approach to teaching entrepreneurship is associated with superior outcomes in comparison to the traditional approach. It focuses on perceived learning outcomes specifically and applies the tripartite competence framework to assess them. Building on experiential entrepreneurship education, theory of planned behaviour and social learning theory of self-regulation, the authors hypothesize that experiential entrepreneurship education is associated with a significantly higher level of educational outcomes for learners than traditional entrepreneurship education. Furthermore, the authors suggest that skill-based outcomes mediate the relationship between cognitive and affective outcomes.

This study applies a mixed methods embedded design to a sample consisting of eight entrepreneurship educators and 306 recent and 
imminent graduates from entrepreneurship-related bachelor's programs at four Latvian business schools. Main results indicate that more experiential entrepreneurship education does not necessarily lead to higher levels of learning outcomes, in some cases even being associated with adverse effects, and that other factors exhibit significant influence on these outcomes. These intriguing results are discussed and relevant managerial implications are drawn.

To sum up, Part II contributes to entrepreneurship education from four different perspectives. First, Rashan Shah Robuan, Jaén and Liñán describe the unique conditions that act as incentives and barriers to entrepreneurship education, in particular social and cultural contexts, such as in Malaysia. Case studies in entrepreneurship education are very informative and convey relevant information for practice, but they are still scarce. Thus, this study is a contribution to the entrepreneurship evidence-based teaching and policy development. Second, Hägg and Politis contribute to analyze the conditions for entrepreneurial learning among students using formal mentorship. Adding to previous findings, the authors show that psychosocial support is important in the early stage of mentoring, where openness, motivation and commitment create mutual trust within the mentoring dyad. Third, the study by Lyons, Lynn and Mac an Bhaird highlights one important but often neglected aspect, namely the importance of the team and the efficiency of teamwork in the context of entrepreneurship education. Collaborative learning is commonly used in entrepreneurship education and the chapter contributes to a more nuanced knowledge of the mechanisms behind teamwork in entrepreneurship education. Finally, Kozlinska, Mets and Rõigas challenge the assumption that experiential entrepreneurship education works better than the traditional approach. Their mixed methods empirical study developed in Latvia indicates that experiential entrepreneurship education does not always work as expected. This empirical result is intriguing and calls for new research on the perceived learning outcomes of experiential entrepreneurship education.

\subsection{ENTREPRENEURIAL ORIENTATION RESEARCH}

Finally, another strand of research that has received extensive interest over the last 15-20 years is research on 'entrepreneurial orientation' (EO), and EO is one of the few areas within entrepreneurship research where we can claim some form of cumulative body of knowledge. Within this area of research, Danny Miller made an early contribution in his seminal work 'The correlates of entrepreneurship in three types of firms' (1983), 
in which he made an important distinction between entrepreneurship as a behaviour within the firm, rather than focusing on the activities of individual entrepreneurship (see, for example, Gartner, 1988). Miller defines an entrepreneurial firm as (p. 771): 'one that engages in product-market innovation, undertakes somewhat risky ventures, and is first to come up with "proactive" innovations, beating competitors to the punch', that is, according to Miller, entrepreneurial orientation (even though he never used the term) includes a firm's innovativeness, risk-taking and proactiveness.

Over the coming decades, several conceptual developments were made within the area (Lumpkin and Dess, 1996; Covin and Slevin, 1989, 1991):

- EO was transformed from a dependent to an independent dimension in order to explain company performance.

- EO was discussed in terms of a discrete vs. a continuous dimension.

- Two more sub-dimensions, 'autonomy' and 'competitive aggressiveness', were discussed in addition to Miller's original three dimensions.

- A discussion with regard to the possibility of the sub-dimensions varying independently of each other or whether they are expected to co-vary with each other.

Since the early 1990s, an extensive number of studies related to EO have been presented. Linton (2016) identified almost 400 scientific journal articles only over the last five years (2011-15). The studies show a strong homogeneity in the sense that most studies are quantitative, all using a similar measuring instrument, and since the early development in the 1980s and early 1990s, the area has shown comparatively little conceptual development. However, the research shows heterogeneity with regard to the contexts in which the studies have been conducted, for example, including different types of industries and organizations, but also in using a large variety of independent and dependent variables, and mediator and moderator factors. In order to build a stronger knowledge accumulation, over the last decade several state-of-the-art works and meta-analyses have been completed in order to synthesize our knowledge within the area, for example, Rauch et al. (2009), Edmond and Wiklund (2010), and Covin and Wales (2012), to name just a few.

Related to the development of early research on EO, the authors in the final part of the book (Chapters 9 to 11) have elaborated on some of the key issues in EO research. For a long period of time, EO studies have focused on internal as well as external activities influencing EO in a corporate setting. In Chapter 9, entitled 'Assembling the puzzle: the need to assess both the internal and external side of corporate entrepreneurship', Riviezzo analyzes 
if and how the balance between internal and external activities might vary under certain environmental conditions. The study is based on survey data from 224 Italian medium-sized firms operating in the manufacturing industry. The empirical results show that the key variables that may internally affect a company's EO and the use of networking in order to get access to external resources and competences all play a critical role in influencing EO, that is, all these internal and external variables must be considered as pieces of a 'puzzle' to be assembled in order to get a real picture of the phenomenon.

In the next chapter (Chapter 10), entitled 'Linking SMEs' strategic orientation and international performance: insights from an empirical investigation in Italy' by Riviezzo and Garofano, the authors pick up on the heterogeneity of contexts and investigate the role of EO, market orientation (MO) and environmental conditions on international performance of SMEs. In this chapter the authors pay particular attention to the moderating effect of the domestic market. The authors conclude that both EO and MO, understood as strategic orientations, influence international performance of SMEs, when both these strategic orientations coexist. Contrary to what they hypothesized, Riviezzo and Garofano find that the more hostile and dynamic the domestic market is, together with the challenges that creates, the more firms are required to commit their activities first and foremost to these national markets. The authors conclude by stressing that more sensitivity be directed to the role of the environment regarding different strategic orientations. And thus, hostility and dynamism in a SME's domestic market have a negative relationship with international performance. The authors also find that within hostile domestic markets EO becomes increasingly important for international performance, while the opposite is true for MO.

Finally, in Chapter 11 entitled 'Does entrepreneurial orientation matter to strategic alliances formation: the influence of entrepreneurial orientation and leaders on the success of partnerships in entrepreneurial business', by Oliveira Jr, Oliveira and Bernardes, the authors investigate the relationship between EO and strategic alliances and how this relationship is affected by the entrepreneurial behaviour of the top management team. In the chapter, the authors position EO as a multi-dimensional construct and in particular they find that it is the sub-dimension of risk-taking that mostly explains the prevalence of strategic alliances. This relationship was found to be directly affected by the top management team's entrepreneurial behaviour and mediated by firm size.

To sum up, the chapters in Part III of this volume follow the tradition of the international EO research, while at the same time the chapters include some new insights in EO research. First, Riviezzo strongly emphasizes 
the holistic view on EO and argues that both internal and external variables must be considered to get an understanding of EO in a company. Second, in the next chapter by Riviezzo and Garofano, the authors stress the relationship between the characteristics of the domestic market and the international performance of the company. Interestingly they found that within hostile domestic markets, EO becomes important for international performance, whereas the opposite holds for market orientation. Finally, Oliveira Jr, Oliveira and Bernardes focus in particular on the creation of strategic alliances, and find that 'risk-taking' is the sub-dimension of EO that mostly explains the prevalence of strategic alliances, and also is something that is directly affected by the top management team.

\section{REFERENCES}

Ajzen, L. and M. Fishbein (1969), 'The prediction of behavioral intentions in a choice situation', Journal of Experimental Social Psychology, 5(4), 400-16.

Bird, B. (1988), 'Implementing entrepreneurial ideas: The case for intention', Academy of Management Review, 13(3), 442-53.

Covin, J.G. and D.P. Slevin (1989), 'Strategic management of small firms in hostile and benign environments', Strategic Management Journal, 10(1), 75-87.

Covin, J.G. and D.P. Slevin (1991), 'A conceptual model of entrepreneurship as firm behavior', Entrepreneurship Theory and Practice, 16(1), 7-25.

Covin, J.G. and W.J. Wales (2012), 'The measurement of entrepreneurial orientation', Entrepreneurship Theory and Practice, 36(4), 677-702.

Edmond, V. and J. Wiklund (2010), 'The historic roots of entrepreneurial orientation research', in H. Landström and F. Lohrke (eds), The Historical Foundation of Entrepreneurship Research, Cheltenham, UK and Northampton, MA, USA: Edward Elgar Publishing, pp. 142-60.

Fayolle, A. (2008), 'Entrepreneurship education at a crossroad: Towards a more mature teaching field', Journal of Enterprising Culture, 16(4), 325-37.

Fayolle, A. (2013), 'Personal views on the future of entrepreneurship education', Entrepreneurship and Regional Development, 25(7-8), 692-701.

Fayolle, A. and B. Gailly (2008), 'From craft to science: Teaching models and learning processes in entrepreneurship education', Journal of European Industrial Training, 32(7), 569-93.

Gartner, W.B. (1988), "Who is an entrepreneur?" Is the wrong question', American Journal of Small Business, 12(4), 11-32.

Gibb, A.A. (1987), 'Enterprise culture: Its meaning and implication for education and training', Journal of European Industrial Training, 11(2), 2-38.

Hägg, G. and J. Gabrielsson (2017), 'From behavioral to constructivist action: A systematic review of development in research on pedagogy in entrepreneurship education' (forthcoming).

Johannisson, B. (1991), 'University training for entrepreneurship: Swedish approaches', Entrepreneurship and Regional Development, 3(1), 67-82.

Krueger, N.F. and D.V. Brazeal (1994), 'Entrepreneurial potential and potential entrepreneurs', Entrepreneurship Theory and Practice, 18, 91-104. 
Krueger, N.F. and A.L. Carsrud (1993), 'Entrepreneurial intentions: Applying the Theory of Planned Behaviour', Entrepreneurship and Regional Development, 5(4), 315-30.

Krueger, N.F., M.D. Reilly and A.L. Carsrud (2000), 'Competing models of entrepreneurial intentions', Journal of Business Venturing, 15(5-6), 411-32.

Kyrö, P. (2015), 'The conceptual contribution of education research on entrepreneurship education', Entrepreneurship and Regional Development, 27(9-10), 599-618.

Landström, H. and F. Åström (2011), 'Who's asking the right question? Patterns and diversity in the literature of new venture creation', in K. Hindle and K. Klyver (eds), Handbook of Research on New Venture Creation, Cheltenham, UK and Northampton, MA, USA: Edward Elgar Publishing, pp. 34-71.

Linton, G. (2016), 'Entrepreneurial orientation: Reflections from a contingency perspective', Doctoral Dissertation, Örebro Studies in Business 9, Örebro University, Sweden.

Lumpkin, G.T. and G.G. Dess (1996), 'Clarifying the entrepreneurial orientation construct and linking it to performance', Academy of Management Review, 21, 135-72.

Miller, D. (1983), 'The correlates of entrepreneurship in three types of firms', Management Science, 29(7), 770-91.

Neck, H.M. and P.G. Greene (2011), 'Entrepreneurship education: Known worlds and new frontiers', Journal of Small Business Management, 49(1), 55-70.

Pittaway, L. and J. Cope (2007), 'Simulating entrepreneurial learning: Integrating experiential and collaborative approaches to learning', Management Learning, 38(2), 211-33.

Rauch, A., J. Wiklund, G.T. Lumpkin and M. Frese (2009), 'Entrepreneurial orientation and business performance: An assessment of past research and suggestions for the future', Entrepreneurship Theory and Practice, 33, 761-87.

Shapero, A. and L. Sokol (1982), 'The social dimensions of entrepreneurship', in C. Kent, D. Sexton and K. Vesper (eds), Encyclopedia of Entrepreneurship, Englewood Cliffs, NJ: Prentice Hall, pp. 72-90.

Tubbs, M.E. and S.E. Ekeberg (1991), 'The role of intentions in work motivation', Academy of Management Review, 16(1), 180-99.

Williams Middleton, K. and A. Donnellon (2014), 'Personalizing entrepreneurial learning: A pedagogy for facilitating the know why', Entrepreneurship Research Journal, 4(2), 167-204. 